\title{
Calibration of prover tanks making use of a Coriolis mass flow meter as the master meter
}

F.M. Erik Smits ${ }^{\star}$ and J.C. Jos Rath

VSL (National Metrology Institute of The Netherlands), Thijsseweg 11, 2629 JA Delft, The Netherlands

Received: 5 May 2012 / Accepted: 9 June 2012

\begin{abstract}
Calibration of volumetric proving tanks can be done using different methods. For the calibration of large proving tanks the master meter method can be used as a good alternative to the volumetric transfer method or the gravimetric method. When the master meter method is used in most cases a positive displacement meter is used. A better option is to make use a Coriolis mass flow meter as the master meter. Test data is presented of a calibration of a proving tank with a nominal volume of $500 \mathrm{~L}$. Small repeatability figures can be obtained of consecutive calibration runs with a Coriolis mass flow meter. Also the linearity of the meter factor curve of the Coriolis mass flow meter makes this a better option for the master meter method.
\end{abstract}

Keywords: Calibration; proving tanks; Coriolis mass flow meter

\section{Introduction}

When liquid hydrocarbons are sold from one company to another the amount of liquid is measured under local laws for legal metrology. In most cases this is done by an installation that contains a liquid flow meter to measure the actual volume, volume at reference conditions or mass of the amount of liquid transferred. In most countries reverification of these flow meters needs to be performed at a regular interval. In the field this is mostly done by collecting the liquid into a proving tank in order to prove the delivered volume of the liquid flow meter (volume and/or mass). The proving tanks also need to be recalibrated at a regular interval. There are several methods to do this. For proving tanks with large volumes this is a complex task because it is not possible to use the gravimetrical method since most laboratories do not have weighing scales which are big enough. The proving tank can also be part of a facility and cannot be shipped to the laboratory. In most cases smaller proving tanks are used to perform the calibration $(10 \times 100=1000 \mathrm{~L})$. This method is known as the "volumetric transfer method". This is a time consuming and labour intensive method and can introduce systematic measurement errors. An alternative method to establish the reference volume of the proving tank is the so-called "master meter method". A liquid flow meter (master meter or reference meter) is calibrated against a reference standard at the laboratory or on location and then used to calibrate the proving tank. The calibration of the master meter can be done against a weighing scale, reference (master) proving tank or a pipe prover. Common practice

\footnotetext{
${ }^{\star}$ Correspondence: fsmits@vsl.nl
}

until now is the use of PD type flow meters as the master meter. In this paper we will show that a Coriolis mass flow meter is at least as good or maybe an even better option than PD flow meters since PD flow meters are affected by temperature changes and the meter curve can influence the outcome of the calibration. It is even possible to just use a Coriolis mass flow meter without a reference standard if used in the correct flow range of the Coriolis mass flow meter. The measurement uncertainty calculations show no differences between the liquid flow meter types. It also makes it possible to calibrate with hydrocarbon as test medium instead of water.

\section{Prior knowledge and boundaries for this paper}

The master meter method is used to calibrate a variety of instruments like flow meters, pipe provers and proving tanks. This method is described in many standards and best practice guides. Many laboratories and companies that perform calibrations using the master meter method refer to the Manual of Petroleum Measurement Standards from the American Petroleum Institute (API) [1].

We need to set some boundaries for this paper as it is impossible to go into all aspects. We will present a calibration using a Coriolis mass flow meter as the master meter to establish the volume of a proving tank. We sometimes will relate this to the use of a PD meter since this is common knowledge as laid down in standards.

To be sure that the master meter method works for the calibration of proving tanks VSL performed a method 


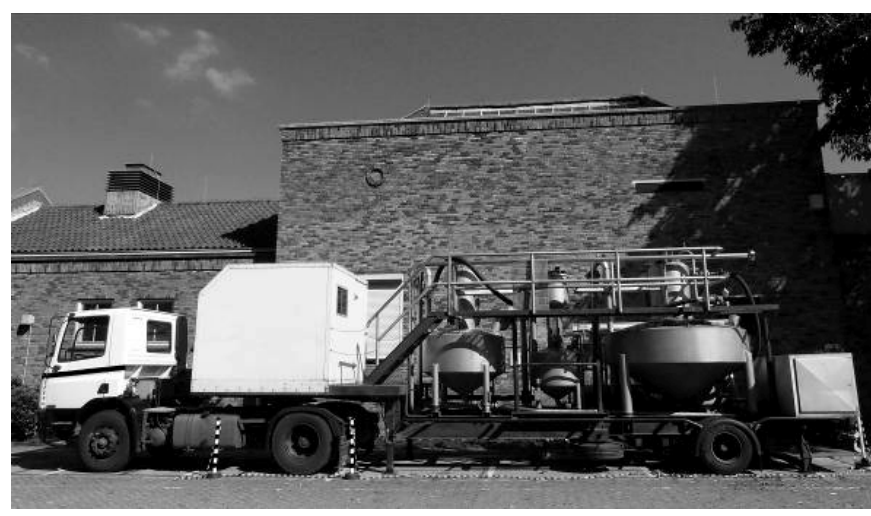

Fig. 1. Proving tanks 500, 1500 and $4000 \mathrm{~L}$ on trailer.

comparison between the gravimetric method and the master meter method using a Coriolis mass flow meter. For this comparison 3 proving tanks with a nominal volume of 50, 100 and $1000 \mathrm{~L}$ were used and two Coriolis mass flow meters of different manufactures as the master meters. The results of this comparison between the two methods show only a small difference in volume of the proving tanks. The biggest difference found was less than $0.003 \%$ in the calculated volume.

\section{Setup of the calibration}

After completing the calibration method comparison the master meter method was used to calibrate four large proving tanks of 500, 1500, 2500 and $4000 \mathrm{~L}$ (Fig 1). These proving tanks have a calibration history of at least 15 year making use of the master meter method and in some cases the gravimetric method. In the past the calibration was performed making use of a PD meter. In the calibration setup one Coriolis mass flow meter with an inlet diameter of $50 \mathrm{~mm}$ was used during all calibrations and during one of the calibrations a second Coriolis mass flow meter with an inlet diameter of $80 \mathrm{~mm}$ was used. The Coriolis mass flow meters are from two different manufactures and were mounted in series. Two weighing scales with a maximum load of 10000 and $3500 \mathrm{~kg}$ where used to calibrate the master meters according to the gravimetrical method. The resolutions for the read out of these weighing scales are 0.05 and $0.02 \mathrm{~kg}$.

In this paper we will focus on the calibration of the $500 \mathrm{~L}$ proving tank and where needed the information of the other proving tanks is also included. The used flow rate was $250 \mathrm{~kg} / \mathrm{min}$. All calibrations and tests are performed using the Water Flow calibration facility of VSL in The Netherlands located in the city of Dordrecht (Figs. 2 and 3). This facility is the National Standard for liquid flow measurements in The Netherlands and has one of the lowest CMC's in the world for mass, mass flow, volume and volume flow. It holds entries in CMC database for NMI's under the CIPM MRA at BIPM as low as $0.02 \%$. This also implies that VSL holds a ISO/IEC17025 [2] accreditation by the Dutch council for accreditation RvA

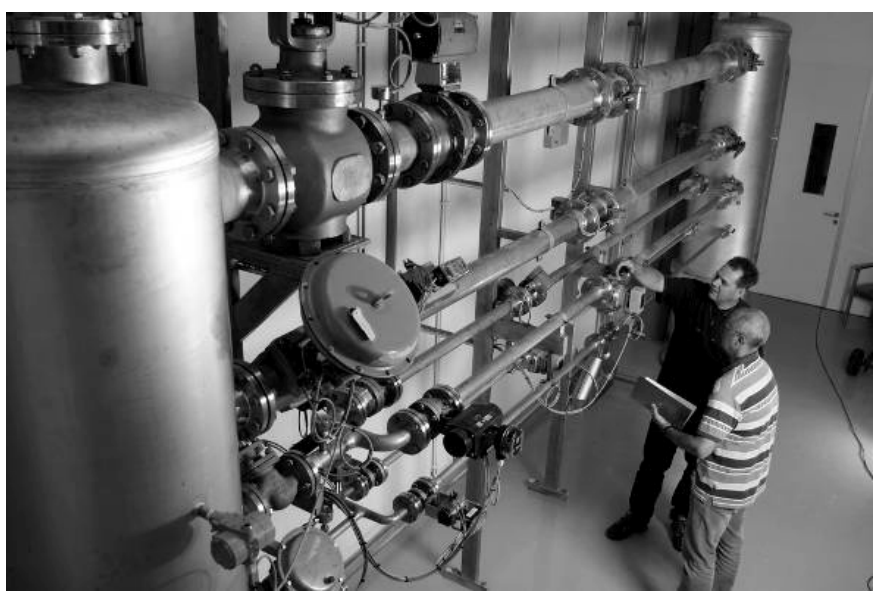

Fig. 2. Master meter section VSL water flow calibration facility.

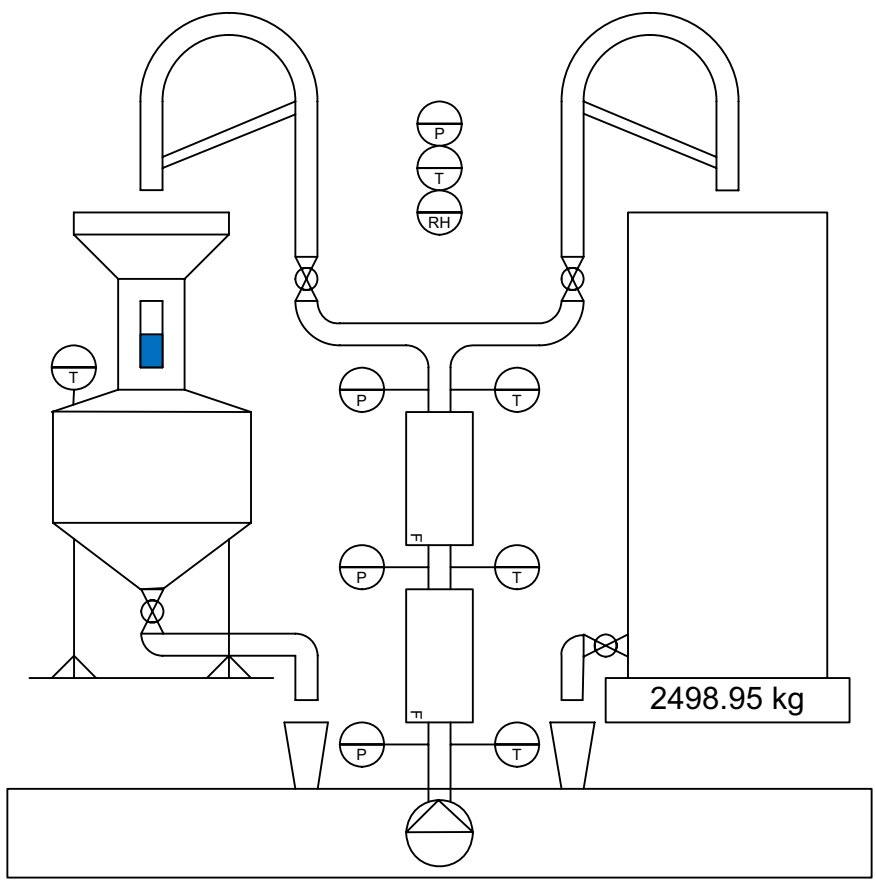

Fig. 3. Schematic calibration setup.

under number K999. The CMC and measurement uncertainty for the master meter method are calculated according JCGM 100:2008, evaluation of measurement data Guide to the expression of uncertainty in measurement (GUM) [3].

Using a Coriolis mass flow Meter is not as easy as the use of a positive displacement (PD) meter and you always need to make sure that the Coriolis mass flow meter is setup in the correct way. This includes the piping configuration, insulation, and the connection to the proving tank but also includes the correct setup of the parameters in the electronics. Before the calibrations took place it was checked whether the Coriolis mass flow meters were connected and setup correctly for the use during the calibration. It is also necessary to make sure that the liquid pressure is almost the same when flow goes to the weighing 
tank or proving tank. For setting up the Coriolis mass flow meter the manual of the manufacturer was used as well as ISO 10790:1999, measurement of fluid flow in closed conduits - Guidance to the selection, installation and use of Coriolis meters (mass flow, density and volume flow measurements) [4].

At least the following calibration sequence was used at a convenient flow rate that made it possible to have flow for at least 2 min during a calibration run. Start with three calibration runs or more of the Coriolis mass flow meters against the weighing scale to establishing the Meter Factor of the Coriolis mass flow meters in mass and volume. Five or more calibration runs to establish the volume of the proving tanks making use of the Coriolis mass flow meters volume and mass readings. Finish with three or more calibration runs of the Coriolis mass flow Meters against the weighing scale establishing the Meter Factor in mass and volume.

The average Meter Factors of the start and finish calibration runs were used to establish the volume.

During the calibration of the $500 \mathrm{~L}$ proving tank the following calibration sequence was used. Five start calibration runs, ten volume calibration runs and five finish calibration runs.

\section{Calculation of the volume of the proving tank}

To calculate the volume using the master meter method with a Coriolis mass flow meter both the mass and volume readings of the meter can be used. The volume calculation is the same when using a PD meter.

\subsection{Calculation using mass indication}

\subsubsection{Calibration of the master meter using the gravimetrical method}

Reference mass passed through the master meter:

$$
M_{\mathrm{ref}} \frac{\left(M_{\mathrm{stop}}-M_{\mathrm{start}}\right)\left(1-\frac{\rho_{\mathrm{a}}}{\rho_{\mathrm{M}}}\right)}{\left(1-\frac{\rho_{a}}{\rho_{L}}\right)}
$$

where:

$M_{\text {ref }} \quad$ Reference mass passed through master meter; meter;

$M_{\text {stop }} \quad$ Indication of the weighing scale at the end of a calibration run;

$M_{\text {start }}$ Indication of the weighing scale at the start of a calibration run;

$\rho_{\mathrm{a}} \quad$ Density of air;

$\rho_{\mathrm{M}} \quad$ Density of the used weights;

$\rho_{\mathrm{L}} \quad$ Density of the used liquid.

Mass Meter Factor of the master meter:

$$
M M F=\frac{M_{\text {ref }}}{M_{\text {ma-mm }}}
$$

where:

MMF Mass Meter Factor of the master meter;

$M_{\text {ref }} \quad$ Reference mass passed through master meter;

$M_{\text {ind-mm }} \quad$ Indicated mass by the master meter.

4.1.2 Calibration of the proving tank using the master meter method

Volume of proving tank at reference conditions:

$$
V_{\mathrm{pt}-\mathrm{ref}}=\frac{\left(M_{\mathrm{ind}-\mathrm{mm}} M M F\right)}{\rho_{\mathrm{pt}}\left(1+\gamma_{\mathrm{pt}}\left(T_{\mathrm{pt}}-T_{\mathrm{pt}-\mathrm{ref}}\right)\right)}-R_{\mathrm{pt}}
$$

where:

$V_{\text {pt-ref }} \quad$ Volume of proving tank at the reference temperature;

$M_{\text {ind-mm }} \quad$ Indicated mass by the master meter;

$M M F \quad$ Mass Meter Factor of the master meter;

$\rho_{\mathrm{pt}} \quad$ Density of the liquid inside the proving tank*;

$\gamma_{\mathrm{pt}} \quad$ Cubical thermal expansion coefficient of the proving tank material;

$T_{\mathrm{pt}} \quad$ Temperature in the proving tank;

$T_{\mathrm{pt-ref}} \quad$ Reference temperature of the proving tank;

$R_{\mathrm{pt}} \quad$ Reading of the proving tank in relation to the zero stripe.

\subsection{Calculation using volume indication}

\subsubsection{Calibration of the master meter using the gravimetrical method}

Reference volume passed through the master meter:

$$
V_{\text {ref }}=\frac{\left(M_{\text {stop }}-M_{\text {start }}\right)\left(1-\frac{\rho_{\mathrm{a}}}{\rho_{\mathrm{M}}}\right)}{\left(\rho_{\mathrm{a}}-\rho_{\mathrm{M}}\right)\left(1+\beta P_{\mathrm{mm}}\right)}
$$

where:

$V_{\text {ref }} \quad$ Reference volume passed through master meter;

$M_{\text {stop }}$ Indication of the weighing scale at the end of a calibration run;

$M_{\text {start }}$ Indication of the weighing scale at the start of a calibration run;

$\rho_{\mathrm{a}} \quad$ Density of air

$\rho_{\mathrm{M}} \quad$ Density of the used weights;

$\rho_{\mathrm{L}} \quad$ Density of the used liquid;

$\beta \quad$ Compressibility factor of the liquid;

$P_{\mathrm{mm}} \quad$ Pressure in the master meter.

Volume Meter Factor of the master meter:

$$
V M F=\frac{V_{\text {ref }}}{V_{\text {ind-mm }}}
$$

where:

$V M F \quad$ Volume Meter Factor of the master meter;

$V_{\text {ref }} \quad$ Reference volume passed through master meter; $V_{\text {ind-mm }}$ Indicated volume by the master meter. 
4.2.2 Calibration of the proving tank using the master meter method

Volume of proving tank at reference conditions:

$$
V_{\mathrm{pt}-\mathrm{ref}}=\frac{\rho_{\mathrm{mm}}\left(V_{\mathrm{ind}-\mathrm{mm}} V M F\right)\left(1+\beta P_{\mathrm{mm}}\right)}{\rho_{\mathrm{pt}}\left(1+\gamma_{\mathrm{pt}}\left(T_{\mathrm{pt}}-T_{\mathrm{pt}-\mathrm{ref}}\right)\right)}
$$

where:

$$
\begin{aligned}
& V_{\text {pt-ref }} \quad \text { Volume of proving tank at the reference } \\
& \text { temperature; } \\
& \rho_{\mathrm{mm}} \quad \text { Density of the liquid in the master meter; } \\
& V_{\text {ind-mm }} \quad \text { Indicated volume by the master meter; } \\
& V M F \quad \text { Volume Meter Factor of the master meter; } \\
& \beta \quad \text { Compressibility factor of the liquid; } \\
& P_{\mathrm{mm}} \quad \text { Pressure in the master meter; } \\
& \rho_{\mathrm{pt}} \quad \text { Density of the liquid inside the proving } \\
& \text { tank*; } \\
& \gamma_{\mathrm{pt}} \quad \text { Cubical thermal expansion coefficient of the } \\
& \text { proving tank material; } \\
& T_{\mathrm{pt}} \quad \text { Temperature in the proving tank; } \\
& T_{\text {pt-ref }} \quad \text { Reference temperature of the proving tank; } \\
& R_{\mathrm{pt}} \quad \text { Reading of the proving tank in relation } \\
& \text { to the zero stripe. }
\end{aligned}
$$

* Density of water is calculated making use of the water density equation recommended by BIPM. This is the socalled Tanaka equation [5]. The input is the temperature observed in the proving tank. Temperature measurement and correction are done according ISO 8222:2002 [6] and

\begin{tabular}{|c|c|c|c|}
\hline \multicolumn{4}{|c|}{ Five calibration start runs } \\
\hline $\begin{array}{c}\text { Run } \\
(-)\end{array}$ & $\begin{array}{c}\text { Flow } \\
(\mathrm{kg} / \mathrm{min})\end{array}$ & $\begin{array}{c}M M F \\
(-)\end{array}$ & $\begin{array}{c}M M F \\
(-)\end{array}$ \\
\hline Start 1 & 249.0 & 0.99956 & 0.99973 \\
\hline Start 2 & 249.0 & 0.99956 & 0.99971 \\
\hline Start 3 & 248.5 & 0.99966 & 0.99981 \\
\hline Start 4 & 249.5 & 0.99964 & 0.99980 \\
\hline Start 5 & 248.7 & 0.99960 & 0.99976 \\
\hline \multicolumn{2}{|c|}{ Average $(-)$} & 0.99960 & 0.99976 \\
\hline
\end{tabular}
OIML R120 [7].

\section{Test data and calibration results}

\begin{tabular}{|c|c|c|c|}
\hline \multicolumn{4}{|c|}{ Ten calibration runs to establish the volume } \\
\hline $\begin{array}{c}\text { Run } \\
(-)\end{array}$ & $\begin{array}{c}\text { Flow } \\
(\mathrm{kg} / \mathrm{min})\end{array}$ & $\begin{array}{c}V_{\text {pt-ref }}(\mathrm{M})^{*} \\
(\mathrm{l})\end{array}$ & $\begin{array}{c}V_{\text {pt-ref }}(\mathrm{V})^{* *} \\
(\mathrm{l})\end{array}$ \\
\hline Vol 1 & 250.0 & 500.28 & 500.25 \\
\hline Vol 2 & 249.8 & 500.25 & 500.23 \\
\hline Vol 3 & 250.0 & 500.21 & 500.20 \\
\hline Vol 4 & 249.5 & 500.22 & 500.21 \\
\hline Vol 5 & 249.2 & 500.21 & 500.20 \\
\hline Vol 6 & 249.5 & 500.22 & 500.22 \\
\hline Vol 7 & 249.9 & 500.19 & 500.19 \\
\hline Vol 8 & 249.4 & 500.22 & 500.22 \\
\hline Vol 9 & 250.0 & 500.26 & 500.26 \\
\hline Vol 10 & 249.2 & 500.24 & 500.24 \\
\hline \multicolumn{2}{|c|}{ Average (l)) } & 500.23 & 500.22 \\
\hline \multicolumn{2}{|c|}{ Standard dev. mean (\%) } & 0.0016 & 0.0015 \\
\hline \multicolumn{2}{|c|}{$\Delta$ Max-Min (\%) ${ }^{* * *}$} & 0.017 & 0.013 \\
\hline
\end{tabular}

For the calibration of the $500 \mathrm{~L}$ proving tank five calibration runs where performed at the start to calculate the meter factors (Tab. 1), ten calibration runs for the volume (Tab. 2) and five calibration runs at the end to calculate the meter factor again (Tab. 3).

During all measurements the liquid pressure was kept

\begin{tabular}{|c|c|c|c|}
\hline \multicolumn{4}{|c|}{ Five calibration closing runs } \\
\hline Run & Flow & $M M F$ & $V M F$ \\
\hline$(-)$ & $(\mathrm{kg} / \mathrm{min})$ & $(-)$ & $(-)$ \\
\hline End 1 & 249.2 & 0.99959 & 0.99974 \\
\hline End 2 & 249.0 & 0.99953 & 0.99969 \\
\hline End 3 & 246.4 & 0.99955 & 0.99972 \\
\hline End 4 & 247.0 & 0.99961 & 0.99978 \\
\hline End 5 & 248.6 & 0.99964 & 0.99982 \\
\hline \multicolumn{2}{|c|}{ Average $(-)$} & 0.99958 & 0.99975 \\
\hline$\Delta \mathrm{MF}$ & tart Run $(\%)^{*}$ & 0.0019 & 0.0013 \\
\hline Stand & v. mean $(\%)^{* *}$ & 0.0013 & 0.0014 \\
\hline
\end{tabular}
between 2.2 and $2.3 \times 10^{5} \mathrm{~Pa}(\mathrm{~g})$. This was done as the used Coriolis mass flow meter has a pressure correction of $-0.012 \%$ per $10^{5} \mathrm{~Pa}$. During flow the liquid pressure may and will vary a little bit. An uncertainty is introduced for the fluctuation of the liquid pressure and the change in liquid pressure during the calibration runs to establish

Table 1. Calibration start runs.
Table 2. Calibration runs.

* Calculating using the mass indication of the master meter. ** Calculating using the volume indication of the master meter. *** The maximum difference between the maximum and minimum found volumes.

Table 3. Calibration closing runs.

* According to API MPMS an absolute difference of $0.02 \%$ is allowed. In all calibrations this difference was never bigger than $0.008 \%$. During many calibrations with PD meters this allowable limit was always close to $0.02 \%$.

** Calculated over 5 start en 5 closing calibration runs.

the meter factors (mass and volume) and the reference volume of the proving tank (change of flow path).

During the calibration the minimum and maximum liquid temperatures varied between 20.11 and $20.32{ }^{\circ} \mathrm{C}$.

It took almost five hours to complete the calibration. This includes the time to flow, waiting time to make a reading and drain time.

In the tables a summary of the results can be found.

\section{Possible measurement uncertainty difference between the use of PD meters and Coriolis mass flow meters}

In this chapter only the possible differences in measurement uncertainties between the two meter types are described. 


\subsection{Measurement uncertainty in temperature}

A Coriolis mass flow meter is affected by temperature but the good thing is that the instrument itself corrects for temperature. A temperature sensor is mounted on the tube wall. A temperature calibration is performed by the manufacturer to give each Coriolis mass flow meter a correction factor for temperature. Even when an average temperature shift of $3{ }^{\circ} \mathrm{C}$ occurs between the start and closing runs to establish the meter factor it shows not a lot of difference in results. The results show that the difference was less than $0.002 \%$. During the calibrations of different proving tanks the differences were equal or smaller than this number. During other type of calibrations on Coriolis meters where the temperature was raised intentionally the results show the same independency to temperature change.

For PD meters a stable temperature is needed to make sure the meter factor does not change. At a temperature shift of $3{ }^{\circ} \mathrm{C}$ between the start and closing runs to establish the meter factor it can already exceed the maximum allowable shift of $0.02 \%$. A lot depends what type of PD meter is used but generally spoken the PD meter is much more affected by a change of temperature than a mass flow meter would be. The reason for this is the gap between the housing (body) and the rotor. This rotor can be of any type like sliding vane, oval gears, etc. The leak flow through the gap is depending on the viscosity of the liquid and therefore a PD meter needs to be selected for this type of calibration.

In general it can be assumed that the measurement uncertainty due to temperature change will be smaller for a Coriolis mass flow meter.

\subsection{Measurement uncertainty in pressure}

A Coriolis mass flow meter is affected by pressure but the good thing is that correction can be made for it. It is also possible to connect external pressure devices to Coriolis mass flow meters to allow the instrument to correct by itself. During the calibrations the pressure was kept between 2.2 and $2.3 \times 10^{5} \mathrm{~Pa}$. The contribution to the measurement uncertainty of this difference was calculated. The biggest advantage is that mass is not affected by the compressibility of the liquid used.

A PD flow meter when applying a low pressures $\left(<5 \times 10^{5} \mathrm{~Pa}\right)$ is almost not affected by pressure. The contribution to the measurement uncertainty is so small that it does not show up in the calculations. The largest measurement uncertainty contribution due to pressure when using a PD meter is the change of volume of the liquid used as a consequence of the pressure changes (Eqs. (4) and (6)). The compressibility of a liquid is temperature dependent.

In general the contributions to the measurement uncertainty due to pressure are very small and will be more or less the same when using water as test liquid.

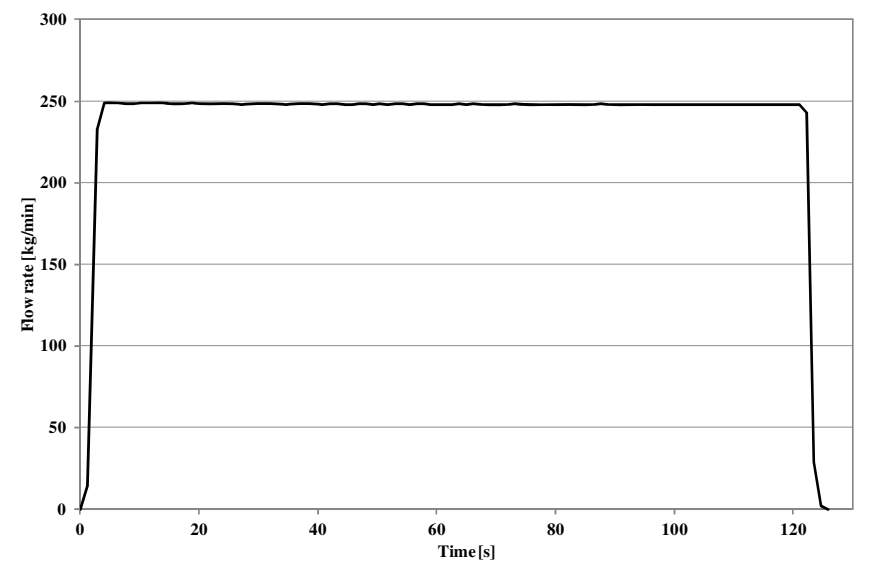

Fig. 4. Flow rate during one calibration run. Note: in Figure 4 you can see that the flow rate is very stable during one calibration run. There are little to no flow rate changes visible.

\subsection{Measurement uncertainty due to Meter Factor curve of a PD meter vs. flow cut off and Meter Factor curve of a Coriolis mass flow meter}

The biggest measurement uncertainty source could be a wrong cut off in the Coriolis mass flow meter. A Coriolis mass flow meter always indicates a little flow even when there is absolutely no flow. Therefore a zero check and/or calibration needs to be performed. The zero check should be done at least before and at the end of the calibration runs. It is recommended to set the zero flow cut off to $0.1 \%$ or smaller. If the flow is ramping up at the start of a calibration run the time that no mass and volume is recorded lasts less than $0.002 \mathrm{~s}$. The same occurs when ramping down. Then the contribution to the measurement uncertainty due to ramping up and down the flow is very small and during the time interval of ramping up and down on average half of the calibration flow rate. For the calibration of the $500 \mathrm{~L}$ proving tank this calculated to be less than $0.010 \mathrm{~kg}$. The good thing is that this happens during the calibration of the Coriolis mass flow meter establishing the meter factors but also when calibrating the proving tank. This measurement uncertainty then is reduced to almost nil and can almost be assumed to show up as random in the repeatability.

The little changes in flow rate during the calibration runs will not introduce measurement uncertainty as the meter factor curve is almost flat for Coriolis mass flow meters (Figs. 4 and 5).

For a PD meter the meter factor curve can be the biggest measurement uncertainty. During ramping up and ramping down the volume indicated is affected by the meter factor curve. It is also very important to choose the correct flow rate for the calibration. If the flow rate chosen for the calibration runs is in a steep part of the meter factor curve then small changes of flow rate will affect the results immensely. According to API MPMS [1] it is allowed to have $5 \%$ flow rate changes if the Meter Factor in this range does not change more than $0.02 \%$. For older master PD meter this can be a problem (Fig. 5). 


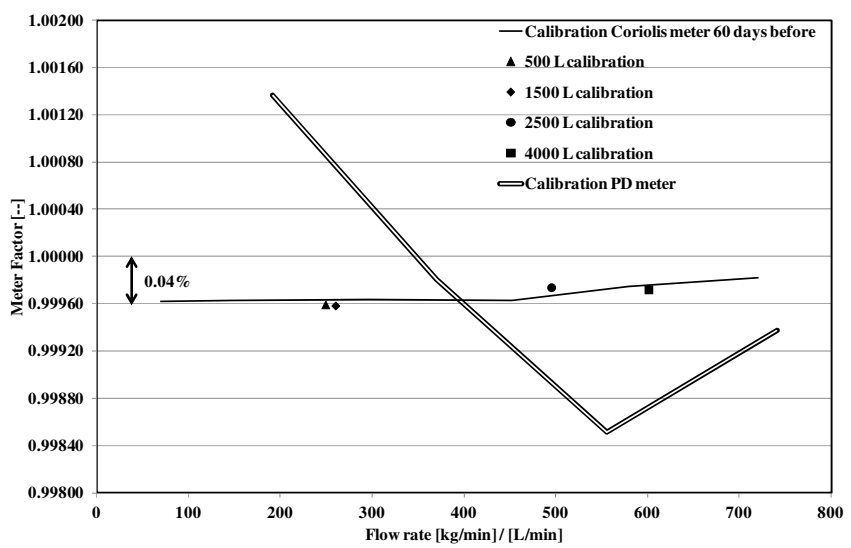

Fig. 5. Meter factors curve of Coriolis mass flow meter and PD meter. Meter factor calibration points of Coriolis mass flow meter during proving tank calibration. Note: the four points shown in Figure 5 (500 L calibration, 1500 L calibration, $2500 \mathrm{~L}$ calibration and $4000 \mathrm{~L}$ calibration) are the found meter factors for the mass reading of the Coriolis mass flow meter. They show small deviations from the original meter factor curve of the Coriolis mass flow meter.

In general the meter factor curves of Coriolis mass flow meters are flatter and therefore will contribute less to the measurement uncertainty both in types $\mathrm{A}$ and $\mathrm{B}$ evaluation of the measurement uncertainty.

\section{Discussion and recommendations}

After performing these calibrations and other tests with Coriolis mass flow meters we can see big improvements in the master meter method. Therefore we would recommend the following discussion:

1. Update the current written standards and best practice guides for the use of the master meter method with Coriolis mass flow meters.

2. It is no longer necessary to use water for the calibration since the biggest uncertainty source for other liquids is the lack of knowledge of the compressibility factor. With Coriolis mass flow meters this factor is not included in the calibration model and is not used.

3. When calculating the measurement uncertainty it shows a smaller expanded uncertainty then before. This is due to the repeatability of the master meter and some other benefits for some measurement uncertainty sources like temperature and meter curve errors. This leads to an improvement of the expanded measurement uncertainty to $0.03 \%$ for the master meter method. It is too early to make this conclusion valid. More proof is needed and a re-calibration of at least these four proving tanks needs to guarantee the new meter type in an already proven method.

\section{Conclusions}

The calculated measurement uncertainty for the master meter method using the VSL water flow facilities of the four calibrations performed are smaller than $0.04 \%$ (in calibration certificates rounded up to $0.04 \%$ ). The calibration data over 15 years show that the band of the volumes found is for all proving tanks about $0.02 \%$. These calibrations include the gravimetrical method and master meter method. Also the methods used vary from time to time but the stability for the proving tanks is better than $0.02 \%$. Therefore the conclusion can be made that the master meter method using a Coriolis mass flow meter is valid.

No start and closing measurements are needed when a Coriolis mass flow meter has been calibrated with the same liquid in the last year (see Fig. 5). There is enough data available to show that Coriolis mass flow meters are stable in time and are not influenced by the liquid temperature and that within limits the meter factor curve will stay valid. There are a few diagnostics that can be used to prove the meter factor curve has not changed. The most important is the zero flow check. A measurement uncertainty of $0.04 \%$ is still achieved when not calibrating the Coriolis mass flow meters Meter Factors. This measurement uncertainty includes the stability in time of the Coriolis mass flow meter Meter Factors (mass and volume).

\section{References}

1. API Manual of Petroleum Measurement Standards, Chaps. 4, 5, 11 and 12, www.api.org

2. ISO/IEC 17025:2005, General requirements for the competence of testing and calibration laboratories, www.iso.org

3. JCGM 100:2008, Evaluation of measurement data - Guide to the expression of uncertainty in measurement (GUM), www.bipm.org

4. ISO 10790:1999, Measurement of fluid flow in closed conduits - Guidance to the selection, installation and use of Coriolis meters (mass flow, density and volume flow measurements), www.iso.org

5. M. Tanaka, G. Girard, R. Davis, A. Peuto, N. Bignell, Recommended table for the density of water between $0{ }^{\circ} \mathrm{C}$ and $40{ }^{\circ} \mathrm{C}$ based on recent experimental reports, Metrología 38, 301-309 (2001), www.bipm.org

6. ISO 8222:2002, Petroleum measurement systems Calibration - Temperature corrections for use when calibrating volumetric proving tanks, www.iso.org

7. OIML R120 (2010) - Standard capacity measures for testing measuring systems for liquids other than water, www.oiml. org 